\title{
Anthropometric parameters and physical fitness in marathon participants with a history of heart disease-an observational study
}

\begin{abstract}
Marathon training is a popular strategy used in cardiac rehabilitation. It may have a role in reducing the risk factors for cardiovascular disease.

Purpose: The aim of the study was to observe the anthropometric parameters and physical fitness in older adults with a history of heart disease and receiving Marathon training as a rehabilitation therapy.

Methods: A multi-centered study was carried out to assess the anthropometric parameters and physical fitness levels in male half marathoners with and without a history of heart disease (Group 1 and 3 respectively). A group of non-marathoners with a history of heart disease was selected as a control group (Group 2). Anthropometric parameters and physical fitness (flexibility and VO2 max) was assessed for all groups.

Results: The weight across the three groups were similar. There was a significant difference $(\mathrm{p} \leq 0.05)$ in mean age, height, waist circumference, WHR, total fat $\%$ and skeletal muscle $\%$ across the 3 groups. All the subjects across the groups were involved in moderate to high intensity aerobic as well as resistance activity for 3 times in a week. The mean waist circumference was found to be more among subjects with history of heart disease as compared to normal range, but a reduced value was observed in mean WHR across the groups. Mean visceral fat an indicator of cardiovascular risks, was found to be high across the groups. According to the mean body fat $\%$, the non-marathoners fell under overweight range and as per the BMI they fell under obese category. All half marathoners (Group 1 and 3) showed mean BMI in overweight range however, the body fat $\%$ was found to be within acceptable limits. This indicates a higher muscle mass and therefore, better body composition in group 1 and 3. Mean flexibility was found to be significantly different $(p=0.032)$ across the groups. Majority of the subjects showed poor flexibility, however, $21 \%$ of half marathoners showed good flexibility. There was also a significant difference in VO2 max level $(\mathrm{p}=0.00)$ between half marathoners with and without a history of heart disease as subjects without a history of heart disease showed better VO2 max level as compared to subjects with history of heart disease.
\end{abstract}

Conclusion: Training strategies used in marathon training can be used to prevent the rising risks for cardiovascular disease in India. Further studies are warranted in this area.

Keywords: marathon, half marathon cardiovascular benefits, CVD risk, visceral fat
Volume 6 Issue 3 - 2017

\section{Sukhada Bhatte Paralkar, Zoya Anis}

Department of Foods, Nutrition and Dietetics, University of Mumbai, India

Correspondence: Sukhada Bhatte Paralkar, Department of Foods, Nutrition and Dietetics, College of Home Science, Nirmala Niketan, University of Mumbai, India, Tel 9820023305, Email sukhada.bhatte@gmail.com

Received: December 19, 2016 | Published: March 03, 2017
Abbreviations: CVD, cardiovascular; WHR, waist to hip ratio; BIA, bioelectrical impedance analysis; BMI, body mass index

\section{Introduction}

Aging leads to changes in the mechanical and structural properties of the vascular wall, which leads to the loss of arterial elasticity and reduced arterial compliance and may subsequently lead to an increased risk for coronary artery disease. ${ }^{1}$ Post a cardiac event most patients are referred for a cardiac rehabilitation program. Cardiac rehabilitation programs usually have a multidisciplinary approach and provides education and counselling services to help heart patients increase physical fitness, reduce cardiac risk factors, improve health and reduce the risk of another cardiac in future. ${ }^{2}$

Many cardiovascular disease patients are remarkably unfit because of illness and inactivity. They can often achieve considerable improvements in exercise capacity from even low- level exercise training. ${ }^{3}$ Resistance training has not been studied extensively in cardiac patients, but some studies suggest that it increases the ability to perform household tasks in frail women with Coronary Artery Disease (CAD) ${ }^{4}$ This may help improve quality of life in older adults. The benefits of half marathon training on anthropometric parameters and fitness levels are not sufficiently studied. High intensity-short duration endurance training for 30 minutes can cause significant improvement in aerobic fitness. ${ }^{5}$

\section{Materials and methods}

The study aim was to observe the anthropometric parameters such as body composition, WHR and physical fitness levels in older adults aged 45 to 65 years with a history of heart disease and receiving marathon training as a rehabilitation therapy. It was a multi centered study, carried out in various centers in Mumbai viz., You 
too can run sports management Pvt. Ltd., Mumbai, Qi Lifecare, Mumbai and Topgear MIG Bandra and Runners Academy, Mumbai. The 45 subjects were divided into 3 groups; Group $1=15$ male half marathoners with history of heart disease, Group $2=15$ male nonmarathoners with history of heart disease and Group $3=15$ male half marathoners without a history of heart disease. Subjects in groups 1 and 3 were half marathoners with and without a history of heart disease (CABG surgery, Angioplasty and Angiography) respectively. While subjects in group 2 were non-marathoners with a history of heart disease. Females subjects and subjects below age 45 and above age $75 y e a r s$ were excluded from the study. It was ensured that the subjects did not suffer from any active ailment/medical condition at the time of the study. Research assistant explained the study in full detail to the subjects and obtained a written consent. After receiving the written consent, the anthropometric parameters were measured and fitness tests were performed (Figure 1).

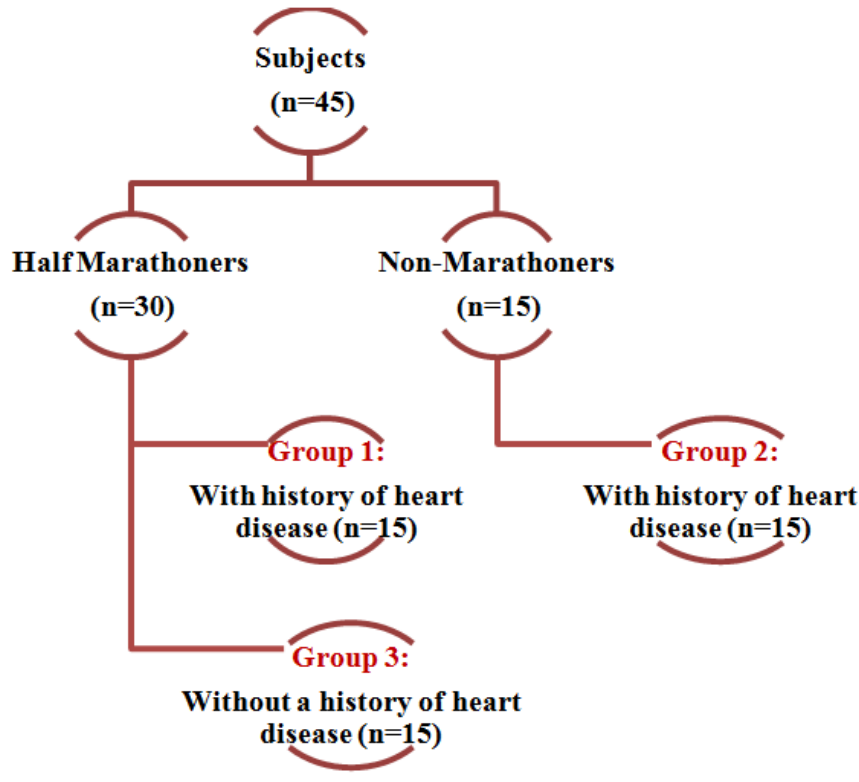

Figure I Study design.

\section{Demographic information}

The demographic information of the subjects as shown in Table 1 was collected at the beginning of the study. The anthropometric parameters studied were as follows:

Table I Demographic information of the subjects
Anthropometric measurements: Anthropometric measurements were used to compare the body composition of the participants across three groups. It is an established fact that higher body fat percentage and visceral fat is associated with metabolic and cardiovascular disease risk.

Height, weight and BMI (Body Mass Index): Height measurements in $\mathrm{cm}$ using a calibrated height scale and weight measurements inkg using an Omron HBF 375 weighing scale were taken. BMI was calculated as per $\mathrm{BMI}=\left(\right.$ weight inkg) $/\left(\right.$ height in $\left.\mathrm{m}^{2}\right)$ equation. Based on the BMI classification for Asian Indians, the subjects were screened for their weight categories.

Waist and hip circumference and waist to hip ratio (WHR): Waist and Hip circumference measurements were recorded in inches using flexible non-stretchable measuring tape. Waist to Hip Ratio (WHR) was calculated as WHR= (waist circumference in inches) (hip circumference in inches). Waist circumference and WHR is a predictor of cardiovascular disease it associated risk factors.

Bioelectrical impedance analysis (BIA): The Omron HBF 375 was used to assess skeletal muscle (\%), visceral fat (\%), subcutaneous fat $(\%)$ and total fat $(\%)$. Measurements were made in the morning before, the training for marathon began. Subjects were informed not to drink plenty of water or caffeinated drinks 4 hours prior to the appointment.

\section{Fitness assessments}

Fitness assessments focused on the flexibility cardiovascular fitness and aerobic endurance. It is important people who run half marathons have good strength, flexibility and cardiovascular fitness. On the other hand, training for half marathon, may help an individual improve on these fitness aspects. Various cardiac rehabilitation centers use strategies of marathon training to help improve and enhance the physical fitness in patients post a cardiac event.

\section{Flexibility test- (YMCA sit and reach test)}

Modified Sit and Reach Test as per the YMCA protocol was used to assess the lower back and hamstring flexibility in the subjects. Subjects were asked to warm up for 5minutes and then made to sit on the floor (leveled surface) with legs apart (about 1feet apart). Measuring tape was placed in between the legs keeping 14 inches between the heels of the foot. Subjects were asked to flex and then slide their hands over the tape gradually without jerking their body. The flexibility was measured in inches on the tape fixed in between the legs. ${ }^{6}$

\begin{tabular}{|c|c|c|c|c|}
\hline & Group I & Group 2 & Group 3 & Significance \\
\hline Number & $N=15$ & $N=I 5$ & $N=\mid 5$ & - \\
\hline $\begin{array}{l}\text { Description } \\
\text { \& Inclusion } \\
\text { Criteria }\end{array}$ & $\begin{array}{l}\text { Male half marathoners with a } \\
\text { history of heart disease, Aged } \\
45-65 \text { years, Males }\end{array}$ & $\begin{array}{l}\text { Male non-marathoners with a } \\
\text { history of heart disease, Aged } \\
45-65 \text { years, Males }\end{array}$ & $\begin{array}{l}\text { Male half marathoners without } \\
\text { a history of heart disease, Aged } \\
45-65 \text { years, Males }\end{array}$ & - \\
\hline Age (yrs) & $61.27 \pm 7.44$ & $61.6 \pm 7.24$ & $52.2 \pm 7.22$ & $* 0.001$ \\
\hline Height (csm) & $166.6 \pm 7.20$ & $164.13 \pm 7.99$ & $172.07 \pm 5.48$ & $* 0.010$ \\
\hline Weight (kg) & $70.6 \pm 9.54$ & $72.12 \pm 11.03$ & $72.7 I \pm I I .97$ & 0.862 \\
\hline BMI $\left(\mathrm{kg} / \mathrm{m}^{2}\right)$ & $25.67 \pm 3.23$ & $26.66 \pm 2.99$ & $24.52 \pm 3.64$ & 0.217 \\
\hline $\begin{array}{l}\text { Year the heart } \\
\text { surgery was } \\
\text { conducted }\end{array}$ & $2007-20 I 3$ & $2006-2015$ & - & - \\
\hline
\end{tabular}


Table Continued....

\begin{tabular}{llll}
\hline & Group I & Group 2 & Group 3 \\
\hline Number & $\mathbf{N}=15$ & $\mathbf{N}=15$ & $\mathbf{N}=15$ \\
\hline $\begin{array}{l}\text { Average half } \\
\text { marathons } \\
\text { participated }\end{array}$ & $2-27$ & - & Significance \\
$\begin{array}{l}\text { Average time } \\
\text { taken for } 21 \mathrm{~km}\end{array}$ & $02: 19: 07-03: 41: 18$ & -35 & - \\
\hline
\end{tabular}

*level of significance: $\mathrm{p} \leq 0.05$

\section{$\mathrm{VO}_{2}$ max measurements}

$\mathrm{VO}_{2}$ max refers to the maximum amount of oxygen that an individual can utilize during intense or maximal exercise and is expressed as $\mathrm{ml} / \mathrm{kg} / \mathrm{min}$. For half marathoners, Davies-Thompson table was used to compute the $\mathrm{VO}_{2}$ max. Davies-Thompson table predicts $\mathrm{VO}_{2}$ max for equivalent running time (h:min:sec) covering $21 \mathrm{~km}$. Subject's running time was noted, based on which the $\mathrm{VO}_{2}$ max was determined. Whereas for non-marathoners the Rockport 1 mile walk test was used to compute the $\mathrm{VO}_{2}$ max. Rockport 1 mile walk test was performed on a treadmill at the Cardiac Rehabilitation Centre- Qi lifecare, Churchgate, Mumbai. Time (min: sec) required to complete 1 mile walk or $1.6 \mathrm{~km}$ walk were recorded along with the heart rate (beats per minute) post the completion of the walk. $\mathrm{VO}_{2}$ max was then determined using the following formula-

$\mathrm{VO}_{2} \max (\mathrm{ml} / \mathrm{kg} / \mathrm{min})=132.853-(0.0769 \mathrm{x}$ weight in $\mathrm{kgs})$ $(0.3877 \mathrm{x}$ age in years $)+(6.315 \mathrm{x}$ gender $)-(3.2649 \mathrm{x}$ time $)-(0.1565$ $\mathrm{x}$ Heart rate)

Gender: male $=1$; female $=0$

\section{Statistical analysis}

The data on body composition, anthropometric and fitness level were analyzed using SPSS 16.0 version. The data analysis was performed on 3 groups comparatively. ANOVA test was applied to the data.

\section{Results and discussion}

The observational study was conducted between June, 2015 to March, 2016. The sampling used was purposive sampling and the centers were chosen based on expertise to train patients with and without a history of heart disease for half marathons. All subjects coincidentally were males. The demographic characteristics of the participants in the three groups is mentioned in Table 1.

Table 2 Anthropometric Measurements of Subjects ( $n=15$ in each group)

\section{Anthropometric measurements}

The average starting weight for the subjects were similar hence the subjects could be compared for other fitness parameters. All subjects on marathon training had similar training schedules. Majority of subjects $(60 \%$ in group $1 ; 67 \%$ in group 2 and $47 \%$ in group 3$)$ fell under obese category with BMI $>25 \mathrm{~kg} / \mathrm{m}^{2}$. Around $13 \%$ in group 1 , $20 \%$ in group 2 and $33 \%$ in group 3 were in overweight category $\left(\mathrm{BMI}=23\right.$ to $24.9 \mathrm{~kg} / \mathrm{m}^{2}$ ) according to the WHO BMI category for Asian Indians. The mean BMI was lower for group 3 as compared to 1 and 2 and had less number of subjects falling in the obese category. This indicates that the risk for cardiovascular disease based on BMI ranges, was lower in group 3 viz., half marathoners who had no history of heart disease so far.

WHR is an important predictor of incident CVD. ${ }^{7}$ While, waist circumference is a more sensitive index than BMI for identifying the presence of one or more vascular risk factors. There was significant difference in the mean waist circumference and WHR among all 3 groups. Non-marathoners showed higher waist circumference (87\%) and WHR $(27 \%)$ whereas Half marathoners with and without a history of heart disease showed lesser waist circumference $(60 \%$ \& $47 \%$ respectively) and WHR (20\% in both). This confirms that structured physical activity, such as training for half marathon can help reduce waist circumference and thereby, offer cardioprotective benefits.

Body composition was assessed using Omron HBF35. Mean visceral fat was high across the groups. Mean body fat $\%$ was found to be acceptable (18.01-25.99\%) among half marathoners while nonmarathoners fell under overweight category (26.01-37.99\%). There was significant difference in mean skeletal muscle across the group. However, half-marathoners without history of heart disease showed higher skeletal muscle than the normal range. Table 2 shows that half marathon training can significantly increase the metabolically active skeletal muscle, reduce total fat \%, waist circumference and WHR $(\mathrm{p} \leq 0.05)$.

\begin{tabular}{|c|c|c|c|c|}
\hline Variables & Group I Mean \pm SD & Group 2Mean士SD & Group 3 Mean士SD & P Value \\
\hline Waist circumference (inches) & $37 \pm 3.74$ & $39 \pm 3.66$ & $34.53 \pm 3.16$ & $* 0.005$ \\
\hline Waist to hip ratio (WHR) & $0.92 \pm 0.09$ & $0.95 \pm 0.05$ & $0.88 \pm 0.07$ & $* 0.054$ \\
\hline Total fat $\%$ & $25.97 \pm 4.14$ & $30.13 \pm 4.01$ & $24.24 \pm 4.74$ & $* 0.002$ \\
\hline Visceral fat $\%$ & $13.67 \pm 4.94$ & $14.49 \pm 5.76$ & $11 \pm 4.69$ & 0.165 \\
\hline Subcutaneous fat $\%$ & $20.35 \pm 2.80$ & $22.06 \pm 3.32$ & $19.19 \pm 3.24$ & 0.065 \\
\hline Skeletal muscle \% & $27.32 \pm 1.84$ & $25.53 \pm 3.29$ & $28.38 \pm 3.66$ & $* 0.043$ \\
\hline
\end{tabular}

*level of significance: $\mathrm{p} \leq 0.05$ 


\section{Physical fitness assessment}

The goals of cardiac rehabilitation using strategies of training for half marathon are increasing the vascularity of the myocardium, improve HDL cholesterol, improve glucose tolerance and insulin sensitivity, weight management and reduction in blood pressure. The training schedule across the 3 groups is shown in Table 3 .

Table 3 Training schedule across the 3 groups ( $n=15$ in each group)

\begin{tabular}{|c|c|c|c|}
\hline & Training/Practice & Form of exercise & Activity apart from training center \\
\hline $\begin{array}{l}\text { Half marathoners } \\
\text { with a history } \\
\text { of heart disease } \\
\text { (Group I) }\end{array}$ & $\begin{array}{l}\text { You Too Can Run } \\
\text { Sports Management } \\
\text { Pvt. Ltd. }\end{array}$ & $\begin{array}{l}\text { ( } 3 \text { times a week; I and a half an hour at } 85 \% \text { MHR) } \\
\text { running practice, static \& dynamic stretches, core \& back } \\
\text { strengthening, yoga asanas, memory game and posture } \\
\text { correction }\end{array}$ & None \\
\hline $\begin{array}{l}\text { Non-marathoners } \\
\text { with a history of } \\
\text { heart disease }\end{array}$ & $\begin{array}{l}\text { Qi Lifecare's } \\
\text { Cardiac } \\
\text { rehabilitation } \\
\text { center }\end{array}$ & $\begin{array}{l}\text { ( } 3 \text { times a week) aerobic exercises, resistance exercises, } \\
\text { core \& back strengthening and regularly heart rate } \\
\text { monitoring }\end{array}$ & $\begin{array}{l}\text { - } 60 \% \text { early morning walk every } \\
\text { alternate day ( } 30 \text { mins) } \\
\text { - about } 13 \% \text { involved in yoga for } 3 \text { times } \\
\text { in a week. }\end{array}$ \\
\hline $\begin{array}{l}\text { Half marathoner } \\
\text { without a history } \\
\text { of heart disease } \\
\text { (Group 3) }\end{array}$ & $\begin{array}{l}\text { Topgear MIG } \\
\text { Bandra \& Runners } \\
\text { Academy }\end{array}$ & $\begin{array}{l}\text { ( } 3 \text { times a week) running practice, running drills, dynamic } \\
\text { stretches, core \& back strengthening and yoga asanas }\end{array}$ & $\begin{array}{l}\text { About } 13 \% \text { subjects also exercised in a } \\
\text { gym ( } \mathrm{Ihr} .15 \text { mins at high intensity) and } \\
\text { squash ( } 3 \text { times a week) }\end{array}$ \\
\hline
\end{tabular}

As shown in table 3, all the subjects involved in moderate to high intensity aerobic as well as resistance activity for 3 times in a week. Endurance training induces greater improvements in aerobic capacity and associated cardiopulmonary and metabolic variables and more effectively modifies cardiovascular risk factors. Resistance training enhances muscular strength, endurance, and muscle mass.

Flexibility was assessed across the groups using YMCA sit and reach technique and was found to be significantly different $(p=0.032)$. Majority of the subjects showed poor flexibility. However, across the 3 groups, 27\% of half marathoners (Group 1 and 3) showed good flexibility. Also, since half marathoners focus more on their aerobic fitness, there is a possibility they emphasize less on flexibility training. Age factor could also be a possible cause for poor flexibility in the subjects.

$\mathrm{VO}_{2}$ max level of non-marathoners cannot be compared with half marathoners as method used to assess $\mathrm{VO}_{2}$ max for the two groups was different. For Half marathoners with and without a history of heart disease (Group 1 and 3), $\mathrm{VO}_{2}$ max was computed using DaviesThompson method. There is significant difference in $\mathrm{VO}_{2}$ max level $(p=0.00)$ between half marathoners with and without a history of heart disease. Among half marathoners, about 20\% subjects without a history of heart disease (Group 3) showed good to excellent VO $\max$ level. However, very poor $\mathrm{VO}_{2} \max$ level $(67 \%)$ was observed in the subjects with a history of heart disease (Group 1). For nonmarathoners with a history of heart disease (Group 2), $\mathrm{VO}_{2}$ max was computed using Rockport 1 mile walk test. $60 \%$ subjects showed very poor $\mathrm{VO}_{2}$ max level whereas only $13 \%$ subjects showed good level of $\mathrm{VO}_{2}$ max. This could be a result of not indulging in much of regular physical activity in addition to the cardiac rehabilitation.

\section{Conclusion}

Training for half marathon can significantly improve skeletal muscle mass, reduce total body fat $\%$, visceral fat, waist circumference and WHR in people with and without history of heart disease. In fact, the training ensues very similar visceral fat, total body fat and skeletal muscle in both the groups. However, the waist circumference and WHR is higher in half marathoners with a history of heart disease than those without a history of heart disease. Training strategies used to prepare for half marathon can be used to reduce the incidence of cardiovascular diseases in India.

\section{Acknowledgements}

The authors would like to thank Mr. Venkatraman Pichumani, Founder and Owner at You Too Can Run Sports Management Pvt. Ltd., Mumbai, Dr. Kiran Sangani, Consultant in Preventive Cardiology and Rehabilitation, Qi Lifecare, Mumbai, Mr. Kaushik Panchal, Founder and Owner at Runners Academy, Mumbai and Mrs. Suchita Varadkar, Trainer at Topgear MIG Bandra, Mumbai for their help in procuring subjects and Dr Wricha Mishra for valuable inputs in statistical analysis. Without their help this research would not have been possible.

\section{Conflict of interest}

The author declares no conflict of interest.

\section{References}

1. Jousilahti Vartiainen, Tuomilehto Puska. Sex, Age, Cardiovascular Risk Factors, and coronary heart disease: a prospective follow-up study of 14786 middle-aged men and women in Finland. Circulation. 1999;99(9):1165-1172.

2. Jani B, Rajkumar C. Ageing and vascular ageing. Postgrad Med J. 2006;82(968):357-362.

3. Thomas SG Sehesteda, Tine W Hanseb, Michael H Olsena, et al. Measures of overweight and obesity risk of cardiovascular disease; a populationbased study. Eur J Prev Cardiovasc Prev Rehabil. 2010;17(4):486-490.

4. Azadbakht L, Mirmiran P, Esmaillzadeh A, et al. Beneficial effects of a Dietary Approaches to Stop Hypertension eating plan on features of the metabolic syndrome. Diabetes Care. 2005;28(12):2823-2831.

5. Kuno Hottenrott, Sebastian Ludygga, Stephan Schulze. Effects of high intensity training and continuous endurance training on aerobic capacity and body composition in recreationally active runners. J Sports Sci Med. 2012;11(3):483-488

6. YMCA. YMCA Fitness Testing and Assessment Manual. 4th ed. USA: YMCA of Human Kinetics; 2000.

7. Yusuf S, Hawken S, Ounpuu S. Obesity and the risk of myocardial infarction in 27,000 participants from 52 countries: a case-control study. Lancet. 2005;366(9497):1640-1649. 